Article

\title{
Assessing Green Space Potential Accessibility through Urban Artificial Building Data in Nanjing, China
}

\author{
Xindong Du, Xiaoke Zhang *, Huan Wang, Xiaojuan Zhi and Jianyuan Huang * \\ School of Public Administration, Hohai University, Nanjing 211100, China; 20160036@hhu.edu.cn (X.D.); \\ huanwang58@hhu.edu.cn (H.W.); sumra@hhu.edu.cn (X.Z.) \\ * Correspondence: xkzhang@hhu.edu.cn (X.Z.); hjy1964@hhu.edu.cn (J.H.); Tel.: +86-25-83787368 (X.Z.)
}

Received: 24 October 2020; Accepted: 26 November 2020; Published: 27 November 2020

\begin{abstract}
Green spaces play an important role in improving the health and quality of life of urban residents, and environmental justice has become one of the most debated topics for scholars and governments in China. The accessibility of green space has been recognized as an effective method for the assessment of environmental justice. Population and green space are the two basic elements for evaluating green space accessibility. However, high-precision population data are difficult to obtain. To address this issue, we propose a straightforward method to assess green space accessibility using urban artificial building data and investigate how green space distribution is correlated with the population. Our analysis uses urban artificial building data and green space data from 2018 in Nanjing, China. The results show that the overall amount of green space, is not only very low, but also unevenly distributed. From the urban center to the city outskirts, the green space changed representing an M-shaped pattern, while the population sharply declined. Given the serious mismatch between the population and green space, only about $26.4 \%$ and $51.8 \%$ of Nanjing residents could access green space within 400 and $800 \mathrm{~m}$, respectively, which was far below that in cities in developed countries. For residents' wellbeing, governments must consider increasing green space provision and promoting equal access.
\end{abstract}

Keywords: green space; accessibility; spatial equity; environmental justice; urban artificial building data; Nanjing

\section{Introduction}

In the past few decades, humans have greatly changed the landscape of the earth through processes such as deforestation, agricultural expansion, and urbanization [1,2]. Some of these land-use changes, especially where natural land has been converted to built-up land, have negatively affected ecology and the environment, threatening regional sustainable development $[3,4]$. Therefore, land-use change has received continuous attention from scholars, particularly in cities and rapidly urbanizing regions, which are characterized by high population concentration and artificial landscapes [5,6]. Apart from the provision of ecosystem services, green spaces contribute positively to inhabitant recreation, sports, social activity, and so on, which could promote human physical and mental development [7-9]. A growing body of research has confirmed that urban sprawl disrupts natural ecosystems and causes environmental problems, thereby degrading the quality of life in urban areas [10-12].

In other words, green space plays a crucial role in supporting urban people's high quality of life. As green space is important for the wellbeing of residents, it has become one of the fundamental objects of environmental justice research [13,14]. Related research includes the spatial pattern change of green space $[15,16]$, the utility of green space $[7,17]$, and the accessibility of green space $[10,18,19]$. 
Additionally, in recent years, green space provision has become an important element of urban planning worldwide [20,21]. In particular, the accessibility of green space has been recognized as an effective method to assess environmental justice. Green space and population are the basic elements for an accessibility assessment. Whereas the distribution of green space can easily be measured by remote sensing or ground surveys, it is difficult to obtain high-resolution population data because populations are constantly moving. Previous studies have pointed out that the first basic principles of a green accessibility assessment should be citizen-based [18]. Demographic data used in most previous studies were taken from census or statistics, which were generally carried out in a specific administrative unit with an interval of several years. Meanwhile, the administrative unit usually covered at least a few square kilometers or even tens of square kilometers and the resolution of the data was particularly insufficient when the study area was over hundreds of square kilometers [19,22].

Most studies focused on cities in developed countries, which are characterized by high urbanization levels and low population growth rates. Cities with rapid urbanization and population growth have not received sufficient attention, especially in China where serious environmental problems are present, leading the Chinese government to focus on environmental justice [23]. Since the beginning of China's policy of reform and opening to the world in 1978, China has been undergoing rapid urbanization. The urban population grew from $1.74 \times 10^{8}$ in 1978 to $8.13 \times 10^{8}$ in 2017 , with the urbanization rate increasing from $17.92 \%$ to $58.52 \%$ [24]. Previous studies showed that the landscape changed significantly along with urbanization $[25,26]$. However, few studies focused on the accessibility of green space $[10,19,27]$ and high-resolution population data are difficult to obtain. Existing studies mainly rely on population census data at a certain administrative level, which may affect the accuracy of results. In other words, population data are a limiting factor in evaluating green space accessibility.

To address this problem, we proposed an alternative solution to assess population distribution. Buildings are important indicators as they are places where people live and work. In this study, we look at urban artificial buildings to represent the population and assume that the building density was consistent with the population density. This allows us to evaluate the accessibility to green spaces at a finer scale than previous research. We chose Nanjing as our study area because it is undergoing rapid urbanization with a population of more than $8.34 \times 10^{6}$. This paper contributes to the existing literature on the accessibility of urban green space on a finer scale in China. The objectives of this paper are to (1) quantify the spatial pattern of green space, and (2) assess the accessibility of urban green space.

\section{Materials and Methods}

\subsection{Study Area}

Nanjing is the capital of Jiangsu Province, which is one of the most prosperous provinces in China. It is located in eastern China, between the longitudes $118^{\circ} 22^{\prime} \mathrm{E}$ and $119^{\circ} 14^{\prime} \mathrm{E}$, and latitudes $31^{\circ} 14^{\prime} \mathrm{N}$ and $32^{\circ} 37^{\prime} \mathrm{N}$ (Figure 1), covering an area of $6582 \mathrm{~km}^{2}$. This region is characterized by an east Asian monsoon climate with an average annual temperature of approximately $15.4{ }^{\circ} \mathrm{C}$ and an annual rainfall of approximately $1200 \mathrm{~mm}$. According to the Statistical Yearbook of Nanjing, the population grew quickly from $3.38 \times 10^{6}$ in 1978 to $8.43 \times 10^{6}$ in 2018 , and about $82.29 \%$ of the population lived in cities in 2018 compared with about $45.07 \%$ in 1978. The GDP per capita was about USD $2.31 \times 10^{4}$ in 2018 , which was significantly above the national average [28]. Nanjing consists of 11 districts; however, only the central urban area was selected in this study, which we defined as the area within the outer ring road and the Yangtze River. In terms of administrative districts, it includes the areas of Xuanwu, Qinhuai, Jianye, Gulou, parts of Yuhuatai, Qixia, Jiangning, and Lishui, covering an area of $577.44 \mathrm{~km}^{2}$. The population size is more than $5.0 \times 10^{6}$ and is still growing. 


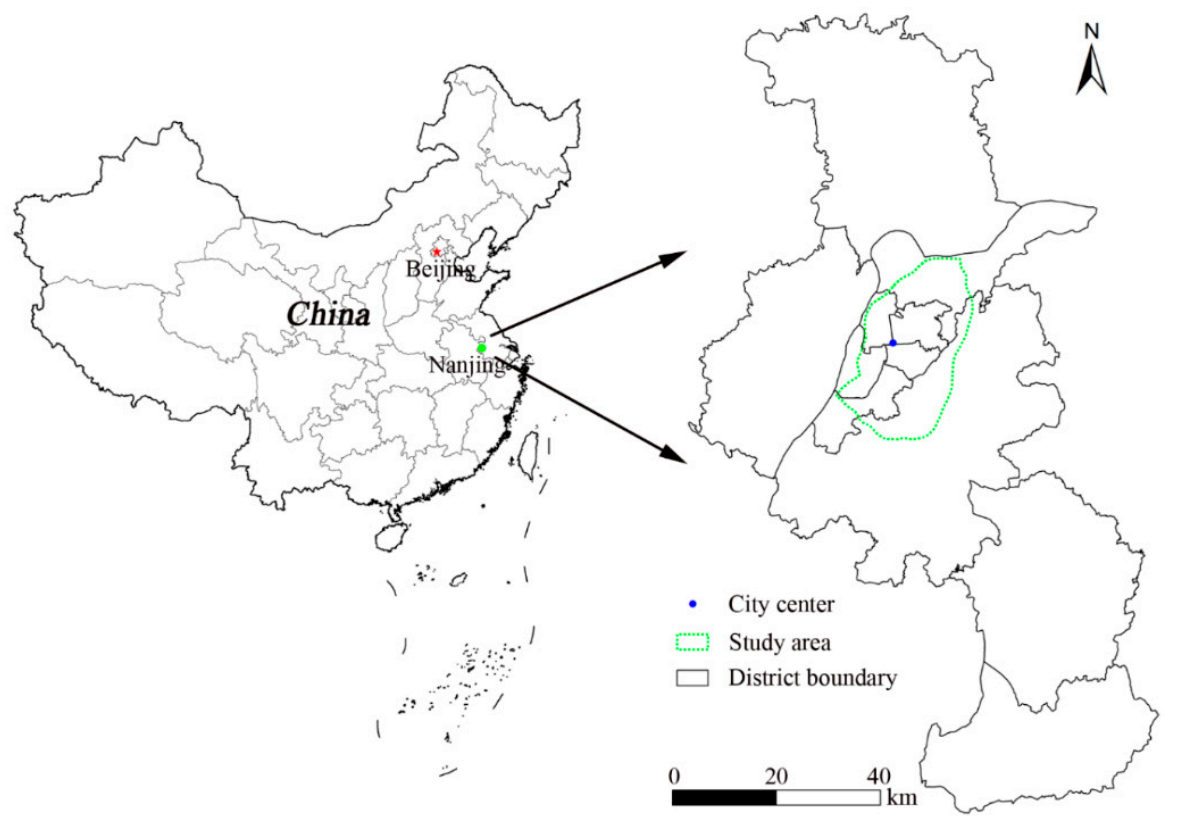

Figure 1. Location of the study area.

\subsection{Data and Pre-Processing}

In this study, urban artificial building data were obtained from the Data Center for Resources and Environmental Sciences at the Chinese Academy of Sciences (RESDC), with a scale of 1:2000, and covering the central urban area. The data contents outline and number the stories of each building in Nanjing in 2018. Referring to previous studies, green spaces are defined as parks, water, and forests where people can relax and spend time. Green space data were obtained from the Nanjing Bureau of Planning and Natural Resources and the Baidu electronic maps (https://map.baidu.com/). Generally, the size of the green space influences its function. However, there is no universal agreement about the standard size of the green space [18]. Based on previous research $[18,20]$, we determined the area of the green space as a space which has a minimum size of 1 ha. All data were plugged into the geographic information system and corrected to the WGS- 84 coordinate system. Then, we overlaid them to extract the central urban area.

\subsection{Methods}

\subsubsection{Spatial Pattern Analysis}

The spatial pattern of green space significantly influences the accessibility analysis, and the spatial distribution of green space is usually uneven. Thus, for our analysis, it was necessary to quantify the spatial pattern of green space. Here, we use Moran's I which has been widely applied to quantify the degree of spatial concentration or dispersion of disasters at a global scale, with the value ranging from -1 (minimum) to 1 (maximum). In general, negative values represent a dispersed pattern or negative spatial autocorrelation and value -1 represents perfect dispersion, whereas positive values represent a clustered pattern or positive spatial autocorrelation and value 1 represents a perfect cluster. Value 0 indicates a random spatial pattern [29]. It should be noted that the index values cannot be interpreted directly. They must be interpreted within the context of the null hypothesis, which is represented by two other parameters, namely z-score and $p$-value. A positive z-score and statistically significant $p$-value indicates that the spatial distribution of objects is a clustered pattern. A negative z-score and statistically significant $p$-value indicates that the spatial distribution of objects is a dispersed pattern.

Along with the process of urbanization, urban sprawl takes place to meet the land demands for the housing, industry, infrastructure, and so on. This causes the landscape to change gradient. In addition to the general spatial pattern, we used gradient analysis to detect green space change 
from the urban center to the fringe, and annuli would be generated at 1000-m intervals. In addition, the spatial pattern analysis of a building uses two indicators, namely building coverage ratio (BCR) and floor area ratio (FAR). BCR is defined as the ratio of building footprint area to the size of the plot upon which it is built, while FAR is the ratio of the building's total floor area to the size of the plot upon which it is built. The spatial pattern analysis was performed using ArcGIS 10.6 software.

\subsubsection{Accessibility Analysis}

There is no consensus in the literature on how to measure access to urban green space $[8,21]$. Generally speaking, distance to green space significantly affects people's travel time and money costs [30]. The closer the space, the lower the cost. Thus, distance to green space is the most important factor for assessing the accessibility of green space. Furthermore, we focused on "daily accessibility" by looking at which surrounding residents could visit certain spaces often on weekdays rather than only on weekends. The walking distance is commonly used to estimate the accessibility of green space $[8,16,19]$. However, there is no clear standard for the length of the walking distance. According to previous studies, a walking distance of $300-800 \mathrm{~m}$ is often determined to evaluate spatial accessibility. In addition, the average walking speed of the elderly and youth was about 1.2 and $1.5 \mathrm{~m} / \mathrm{s}$, respectively [31]. Therefore, we selected 400 and $800 \mathrm{~m}$ as the walking distance, which corresponded to about a 5-min and 10-min walk, respectively. However, we did not consider the specific walking routes and simplified them as Euclidean distances. Then, we created buffer polygons around the green spaces. If a building was located in a buffer polygon, the green space was accessible. Instead, if a building was not located in a buffer polygon this meant the green space was inaccessible.

\section{Results}

\subsection{Provision and Spatial Pattern of Green Space}

As mentioned in the previous section, this study considered a single patch of more than 1 ha in size as a green space. Through this prerequisite, 137 green spaces were selected with a total area of 7492.77 ha, accounting for $13.06 \%$ of the landscape. As shown in Figure 2, green spaces varied in location, size, and spatial form. Out of the total spaces, 84 spaces' areas were less than 10 ha each, accounting for about $61.31 \%$ of the total number of green spaces while occupying only $3.91 \%$ of the total green area. On the contrary, there were eight green spaces whose area was more than 60 ha each and they accounted for more than $81.54 \%$ of the total green area. Particularly, the largest green space was the Purple Mountain Scenic Zone, with an area of 2587.76 ha, accounting for $34.54 \%$ of the total green space. It is located in the east of Nanjing City, with a distance of less than $4 \mathrm{~km}$ from the city center. Green spaces were not distributed equally across the city. They were predominantly distributed in the northeast of Nanjing City within $10 \mathrm{~km}$ of the city center, and south of Nanjing City far away from $(>10 \mathrm{~km})$ the city center. The Moran's I z-score (2.92) and $p$-values (0.00) indicated that the spatial distribution of green space was relatively clustered.

Figure 2 shows the gradient changes of green space from the city center to the fringe. The area of green spaces and its percentage of the total landscape displayed similar changes as the distance to the city center increased. Moving away from the city center, the number of green spaces increased, decreased, and then continuously increased. Corresponding to the spatial distribution, green spaces exceeded the peak in the fifth and the twelfth gradient circles. The area of green space in the gradient circle ranged from 0.77 to 747.74 ha, whereas the percentage of each gradient circle varied from $0.25 \%$ to $20.85 \%$. As the central business district is in the city center, there were a few green spaces in the first and second gradient circles, with 0.77 and 44.24 ha, which accounted for $0.25 \%$ and $4.69 \%$ of each gradient circle, respectively. 


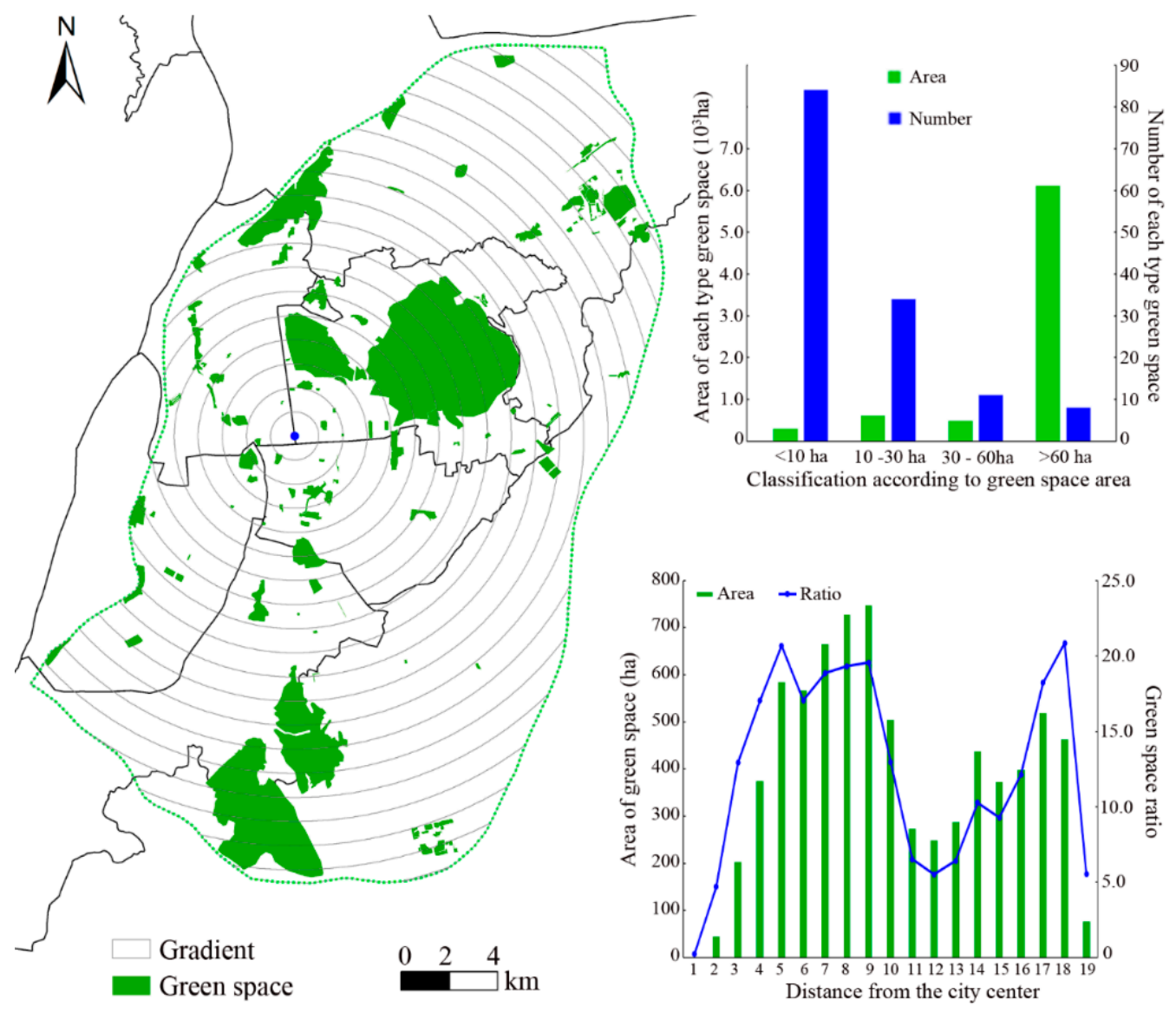

Figure 2. Spatial distribution of green space.

\subsection{Spatial Pattern of Building}

A total of 121,933 buildings are located in the study area, with a building area of 5509.4 and a floor area of 26,205.6 ha. The tallest building is Zifeng Mansion, which is one of the most iconic buildings in Nanjing with 89 stories. It ranks as the 10th tallest building in China and 22nd in the world. Referring to the other studies, we classified the buildings into four categories according to their number of floors: low-rise buildings, in which the number of floors was lower than or equal to 3; multistory buildings, where the number of floors was between 4 and 10; high-rise buildings, with between 11 and 30 floors; and super high-rise buildings, with more than 30 floors. The total building area was approximately 5509.4 ha in the central urban area, with a BCR of $9.65 \%$, which is lower than the green space. However, the FAR measured at $45.84 \%$, with a floor area of $26,205.6 \mathrm{ha}$, which is approximately 3.51 times that of the green space.

Low-rise buildings took up the most space, with an area of 2638.4 ha, followed by multistory buildings ( $2513.5 \mathrm{ha}$ ) and high-rise buildings ( $346.5 \mathrm{ha}$ ). There was only a small number of super high-rise buildings, accounting for $0.2 \%$ of the total building area. However, the floor area of each category differed from its building area. The floor area of multistory buildings exceeded more than half of the total floor area, with a percentage of $55.4 \%$, followed by high-rise buildings (22.8\%) and low-rise buildings (20.2\%). Thus, the difference between the building area and the floor area was significant. As a booming city, many high-rise buildings have been built in Nanjing over the past few decades. In particular, there were 326 buildings with more than 30 stories. Meanwhile, the super high-rise buildings were mainly distributed in two regions. One region was within $2 \mathrm{~km}$ of the city center, and the other was the Hexi Central Business District which was planned as the sub-center of Nanjing.

Figure 3 shows the distribution of buildings and the proportions of different types of buildings. The gradient analysis shows that both FAR and BCR changed synchronously and display declining 
trends as we move from the city center to the fringe. The BCR value was measured at $34.55 \%$ in the innermost circle to $0.59 \%$ in the outermost circle, whereas the FAR value was measured at $248.92 \%$ and then $3.35 \%$.
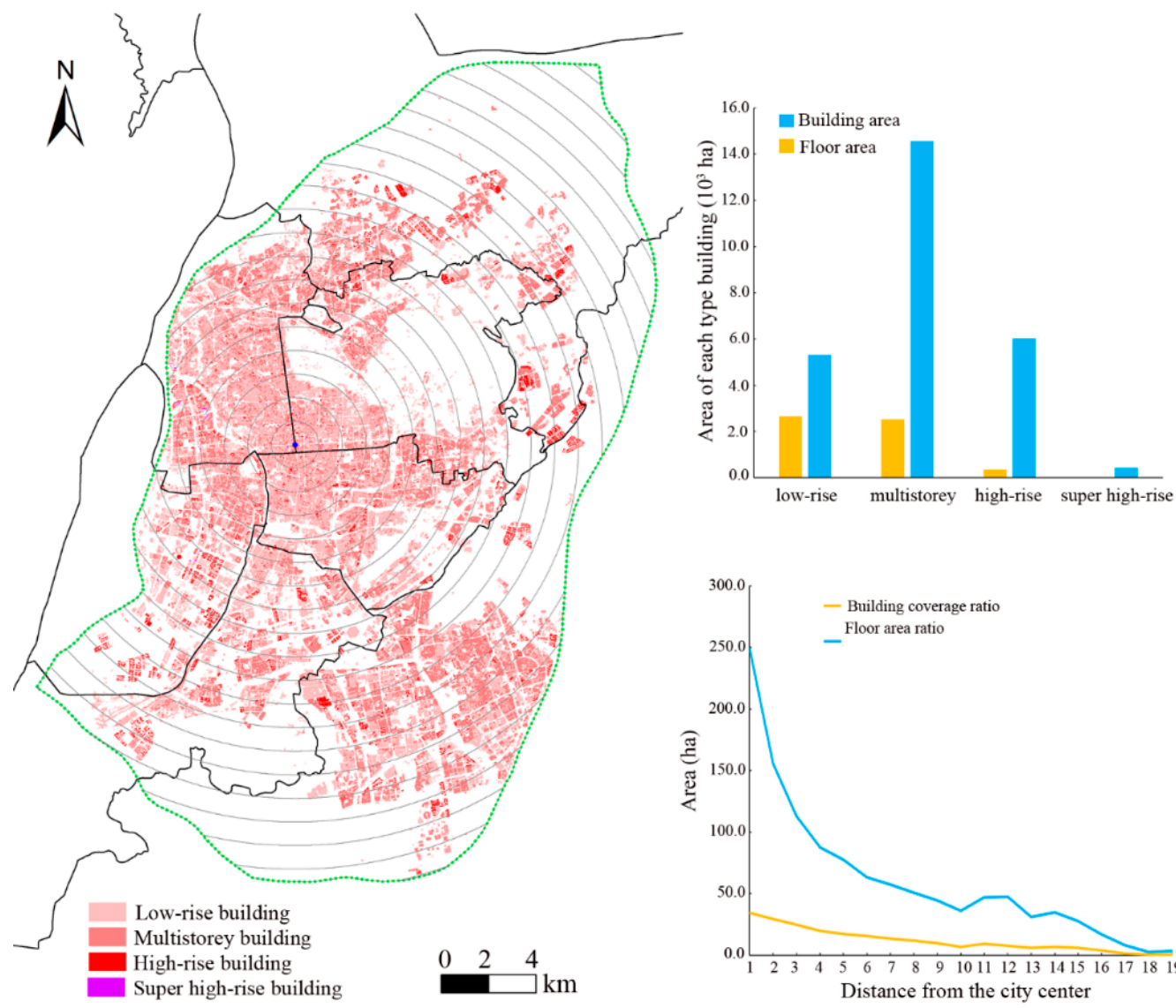

Figure 3. Spatial distribution of buildings.

\subsection{Green Space Accessibility}

As shown in Figure 4, there were 41,579 buildings with a building area of 1552.7 ha and a floor area of 6925.5 ha located in the $400-\mathrm{m}$ buffer polygons of green spaces, measuring $28.2 \%$ of the total building area and $26.4 \%$ of the total floor area. In other words, our data indicate that about a quarter of the residents could conveniently access green space within $400 \mathrm{~m}$ from their homes. Here, there is a serious mismatch between the population and green space. Furthermore, there is a huge discrepancy in the accessibility of green spaces among these buildings. For example, there was only one green space available with an area of less than 10 ha for 11,191 buildings with a floor area of 2054.0 ha, whereas in another area 3189 buildings with a floor area of 427.8 ha could access two green spaces totaling an area of more than 60 ha. Additionally, the average number and area of the accessed green spaces were approximately 1.4 and 318.1 ha, respectively. Due to the significant differences in the area of green space, there is a huge gap between the average value and median value of the accessible green space areas. The median value of the accessible green space area was only 26.4 ha, which was about a twelfth of the average value. In addition, the accessibility of buildings with different heights had some differences too. The super high-rise buildings had the highest accessibility: $37.3 \%$ of these buildings could visit green spaces within $400 \mathrm{~m}$, with $36.2 \%$ of super high-rise floor area having access to green spaces. This was followed by low-rise buildings ( $28.7 \%$ of total low-rise floor area had access to green spaces) and multistory buildings (37.6\% of multistory floor areas had access to green spaces). High-rise buildings had the lowest accessibility and $21.0 \%$ of its buildings were located in the buffer polygons. 

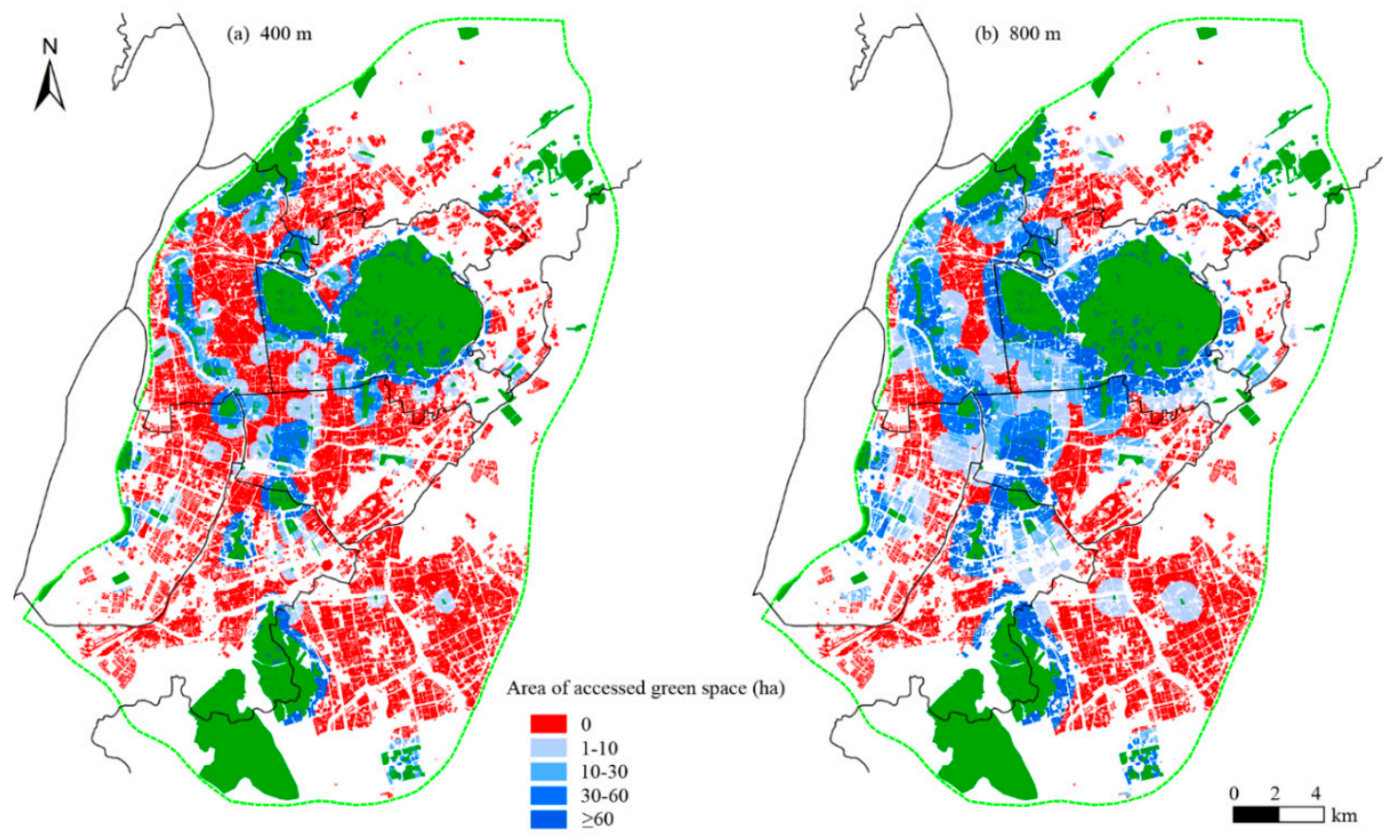

Figure 4. Accessibility of green space within 400 and $800 \mathrm{~m}$.

The number of buildings located in the buffer polygon increased significantly when the buffer radius was set to $800 \mathrm{~m}$. A total of 74,813 buildings could access green spaces within $800 \mathrm{~m}$, with a building area of 1552.7 ha and floor area of 6925.5 ha. However, the respective overall proportion is still unsatisfactory, where $52.9 \%$ of the total building area and $51.8 \%$ of the total floor area could access green spaces. This meant that only slightly more than half of the Nanjing residents could access green space within $800 \mathrm{~m}$. As the walking distance increased, the average number and area of the accessed green space increased to 2.1 and $318.1 \mathrm{ha}$, respectively. The median value of the accessed green spaces was about $44.15 \mathrm{ha}$, which is still far below the average value. In addition, the access ratios among each type of building were similar to those found in the $400 \mathrm{~m}$ buffer. The super high-rise buildings had the highest accessibility, about $67.2 \%$ of their floor area could access green spaces within $800 \mathrm{~m}$. On the contrary, only $48.0 \%$ of the high-rise buildings were within the $800 \mathrm{~m}$ buffer polygon.

Generally speaking, whether the buffer radius was set to $400 \mathrm{~m}$ or $800 \mathrm{~m}$, the green space accessibility of Nanjing was far below that of developed countries [21]. Moreover, our results differ from those in a previous study by Yu et al. [32], where the authors found that $60.44 \%$ of Nanjing residents could access green spaces within $800 \mathrm{~m}$. This difference may largely be caused by "population data." In Yu et al.'s study, population data were represented by 2709 units of housing, while we used more than $1.2 \times 10^{5}$ buildings.

There was a significant difference among the functions of green spaces that residents visited, for the total area of green spaces with an area of less than 10 ha is only one-twentieth of the total area of green spaces with an area of more than $60 \mathrm{ha}$, but the population they serve is about twice the people served by green spaces with an area of more than 60 ha. Green spaces with an area under 10 ha, which accounted for $3.91 \%$ of the total green space area, served most residents, and the building area and floor area of buildings located in its buffer region were 930.41 ha and 4534.50 ha, respectively. Green spaces with areas between 10 and 30 ha followed with about 666.68 ha of building area and 2890.98 ha of floor area distributed in the $500 \mathrm{~m}$ radius of these spaces. However, the building area and floor area in the buffer regions of green spaces larger than 60 ha was much lower than that in the buffer regions of green spaces smaller than 10 ha. We found that 555.15 ha of building area and 2188.01 ha of floor area benefited from green spaces that were larger than 60 ha, which occupied more than $80 \%$ of the total green area. Green spaces between 30 and 60 ha served the fewest residents with roughly 334.90 ha building area, and 1464.70 ha floor area distributed in its buffer regions. 


\section{Discussion}

\subsection{Demographic Data}

Readily available fine spatial resolution population distribution is a key variable for assessing accessibility. In this study, we proposed using building data instead of population data. Although government survey statistics remain a primary method to obtain demographic data, they are carried out in specific administrative units and cost much money and time [33,34]. As administrative units vary in size, and timelines become an issue in the data collection process, it is difficult to directly use these data for studying human-environment interactions, especially for small-scale research areas, such as business decisions, resource allocation, and urban planning [22,35]. Building data (such as building outline, number of floors) have been widely used for modeling high-precision and fine-scale population distribution [36]. For example, Dong et al. [37] found that the mean absolute relative error of population distribution can be improved to $7 \%$ based on residential buildings. Unlike from population estimation studies, we think that the exact number of people is not very important for assessing accessibility. We are more concerned with the proportion of the population that experiences accessibility. In addition, public resources such as urban green space should be equally allocated among all residents.

\subsection{Walking Distance}

The setting of the walking distance length has a great influence on the accessibility assessment. In this study, accessibility increases significantly along with walking distance, similarly to in previous studies [32,38,39]. Furthermore, this indicates that the distance setting may produce different conclusions. Logan et al. [39] show that the portions of the population without green space access in Baltimore and Chicago were considerably different when the walking length increased from $400 \mathrm{~m}$ to $1000 \mathrm{~m}$. The threshold distance setting should consider the maximum distance to urban green space, for the maximum distance changes depending on the city. For example, Wüstemann et al. [21] found that the maximum distance to urban green space ranged from $541 \mathrm{~m}$ in Bergisch Gladbach to $1804 \mathrm{~m}$ in Augsburg across 53 major cities in Germany. Mears and Brindley [38] concluded that almost all residents in Sheffield could access green space within $500 \mathrm{~m}$. In other words, the walking threshold distance setting should be set below the maximum distance to the nearest green space when evaluating accessibility and especially when comparing accessibility in different cities.

\subsection{Green Space Provision}

China has been experiencing rapid urbanization since its reform and opening-up policy in 1978. The landscape has changed dramatically in cities, where natural land has been converted to built-up land, causing the urban environment to deteriorate. For example, the official ratio of green space was only $13.7 \mathrm{~m}^{2}$ per capita in China in 2018 , which was much lower than developed countries, for example, the per capita area of green space in the US is more than $50 \mathrm{~m}^{2}$ and in most German major cities is more than $21 \mathrm{~m}^{2}[8,21]$. Although the government has paid attention to green space planning, this topic has lagged far behind real estate investment. According to the Statistical Yearbook of Nanjing (2018), the annual increase in green space area was about $3.67 \times 10^{7} \mathrm{~m}^{2}$ during the past 10 years, whereas the annual increase in the floor area of buildings completed was up to $1.0 \times 10^{7} \mathrm{~m}^{2}$, and green space per capita was only about $15.5 \mathrm{~m}^{2}$ in 2018. In this study, the total area of green space was about $7492.77 \mathrm{ha}$, which is lower than what previously reported by the official statistics (9991 ha). This might be due to two reasons: (1) the official statistics area included the whole administrative area of Nanjing, whereas we selected the central urban area as the statistics area; and (2) the minimum size in the official statistics was $400 \mathrm{~m}^{2}$, whereas we determined this as 1 ha for our study. We wish to highlight the importance of increasing green space provision. There is a significantly negative correlation between the Gini index (that measures the distribution of income across a population) and per capita green space according to the supplementary data of Wüstemann et al. [21]. Furthermore, the spatial distribution of green space is very important 
and should meet the demand of residents. In this study, most green spaces were distributed far away from the city center and were strongly concentrated in several areas where the land was not suitable for development. For example, the eight largest green spaces were all mountains and lakes. Thus, not only was the total amount of green space insufficient but its spatial distribution was uneven.

\subsection{Limitations and Directions for Future Work}

Given the difficulty in obtaining high-resolution population data for the green space accessibility assessment, in this study, we proposed relying on extensive building data. Despite this novel contribution, our study has some limitations. For instance, we assumed that the building density was consistent with the population density. This assumption may only apply to cities with growing populations, as there are ghost cities in newly developed areas in China [40]. Furthermore, we adopted a buffer overlay analysis, which ignores the actual commute conditions. This may have led to an overestimation of green space accessibility. In addition, green space itself was another important element for the accessibility assessment. Location and area were just two of the many attributes of green space. We did not consider the quality of green space, which can influence whether people use it [41]. These problems need to be addressed in the future. Although there are still some uncertainties, our study can further enhance accessibility assessments of urban areas in China.

\section{Conclusions}

Green space has an important impact on the health and wellbeing of urban residents, and has received increasing attention from various scholars, especially in China, where severe urban environmental problems are experienced. In this study, we explored the spatial pattern of green space in Nanjing, China, and proposed a straightforward method to assess the accessibility of green space based on urban artificial building data. The results showed that the provision of green space in Nanjing was uneven and there was a serious mismatch between the population and the available green space. We found that green space provision increased as the distance from the city center increased, while population density decreased along with the distance from the city center. The results further showed that only about $26.4 \%$ and $51.8 \%$ of the residents could access green space within a 400 and $800 \mathrm{~m}$ buffer around their place of residence, respectively. However, we disregarded road conditions, thus this accessibility may be overrated. Furthermore, nearly three-quarters of residents lacked access to green space within $400 \mathrm{~m}$ of their residence, which indicated that green space distribution was unequal and insufficient. The green space per capita was far below developed countries, therefore governments must consider increasing green space provision and promoting equal accessibility.

Author Contributions: Conceptualization, X.D., X.Z. (Xiaoke Zhang), J.H.; methodology, X.D., X.Z. (Xiaoke Zhang); software, H.W., X.Z. (Xiaojuan Zhi); formal analysis, X.D.; investigation, X.D., X.Z. (Xiaoke Zhang); resources, X.D., H.W.; data curation, H.W.; writing-original draft preparation, X.D., X.Z. (Xiaoke Zhang); writing一review and editing, X.D., J.H.; visualization, H.W.; supervision, X.D.; project administration, X.Z. (Xiaoke Zhang), J.H.; funding acquisition, J.H. All authors have read and agreed to the published version of the manuscript.

Funding: This research was funded by the Fundamental Research Funds for the Central Universities of China (Grant No. 2019B20214), Humanities and social sciences foundation of the Ministry of Education, China (Grant No. 17YJC630228) and the National Natural Science Foundation of China $(41601435,41601139)$.

Acknowledgments: We would like to thank Georgina Kate for English language editing.

Conflicts of Interest: The authors declare no conflict of interest.

\section{References}

1. Song, X.; Hansen, M.C.; Stehman, S.V.; Potapov, P.V.; Tyukavina, A.; Vermote, E.F.; Townshend, J.R. Global land change from 1982 to 2016. Nature 2018, 560, 639-643. [CrossRef] [PubMed]

2. Caballero Espejo, J.; Messinger, M.; Román-Dañobeytia, F.; Ascorra, C.; Fernandez, L.; Silman, M. Deforestation and Forest Degradation Due to Gold Mining in the Peruvian Amazon: A 34-Year Perspective. Remote Sens. 2018, 10, 1903. [CrossRef] 
3. Foley, J.A.; DeFries, R.; Asner, G.P.; Barford, C.; Bonan, G.; Carpenter, S.R.; Chapin, F.S.; Coe, M.T.; Daily, G.C.; Gibbs, H.K.; et al. Global consequences of land use. Science 2005, 309, 570-574. [CrossRef] [PubMed]

4. King, R.S.; Baker, M.E.; Whigham, D.F.; Weller, D.E.; Jordan, T.E.; Kazyak, P.F.; Hurd, M.K. Spatial considerations for linking watershed land cover to ecological indicators in streams. Ecol. Appl. 2005, 15, 137-153. [CrossRef]

5. Gomes, E.; Abrantes, P.; Banos, A.; Rocha, J.; Buxton, M. Farming under urban pressure: Farmers' land use and land cover change intentions. Appl. Geogr. 2019, 102, 58-70. [CrossRef]

6. Rimal, B.; Sharma, R.; Kunwar, R.; Keshtkar, H.; Stork, N.E.; Rijal, S.; Rahman, S.A.; Baral, H. Effects of land use and land cover change on ecosystem services in the Koshi River Basin, Eastern Nepal. Ecosyst. Serv. 2019, 38, 100963. [CrossRef]

7. Tzoulas, K.; Korpela, K.; Venn, S.; Yli-Pelkonen, V.; Kaźmierczak, A.; Niemela, J.; James, P. Promoting ecosystem and human health in urban areas using Green Infrastructure: A literature review. Landsc. Urban Plan. 2007, 81, 167-178. [CrossRef]

8. Wolch, J.R.; Byrne, J.; Newell, J.P. Urban green space, public health, and environmental justice: The challenge of making cities 'just green enough'. Landsc. Urban Plan. 2014, 125, 234-244. [CrossRef]

9. Chiesura, A. The role of urban parks for the sustainability of cities. Landsc. Urban Plan. 2004, 68, 129-138. [CrossRef]

10. Fan, P.; Xu, L.; Yue, W.; Chen, J. Accessibility of public urban green space in an urban periphery: The case of Shanghai. Landsc. Urban Plan. 2017, 165, 177-192. [CrossRef]

11. Brinkmann, K.; Schumacher, J.; Dittrich, A.; Kadaore, I.; Buerkert, A. Analysis of landscape transformation processes in and around four West African cities over the last 50 years. Landsc. Urban Plan. 2012, 105, 94-105. [CrossRef]

12. Dewan, A.M.; Yamaguchi, Y. Land use and land cover change in Greater Dhaka, Bangladesh: Using remote sensing to promote sustainable urbanization. Appl. Geogr. 2009, 29, 390-401. [CrossRef]

13. Rigolon, A.; Browning, M.; Jennings, V. Inequities in the quality of urban park systems: An environmental justice investigation of cities in the United States. Landsc. Urban Plan. 2018, 178, 156-169. [CrossRef]

14. Rigolon, A. A complex landscape of inequity in access to urban parks: A literature review. Landsc. Urban Plan. 2016, 153, 160-169. [CrossRef]

15. Kong, F.; Nakagoshi, N. Spatial-temporal gradient analysis of urban green spaces in Jinan, China. Landsc. Urban Plan. 2006, 78, 147-164. [CrossRef]

16. Nor, A.N.M.; Corstanje, R.; Harris, J.A.; Brewer, T. Impact of rapid urban expansion on green space structure. Ecol. Indic. 2017, 81, 274-284. [CrossRef]

17. Agay-Shay, K.; Peled, A.; Valentin Crespo, A.; Peretz, C.; Amitai, Y.; Linn, S.; Friger, M.; Nieuwenhuijsen, M.J. Green spaces and adverse pregnancy outcomes. Occup. Environ. Med. 2014, 71, 562-569. [CrossRef]

18. Van Herzele, A.; Wiedemann, T. A monitoring tool for the provision of accessible and attractive urban green spaces. Landsc. Urban Plan. 2003, 63, 109-126. [CrossRef]

19. Xiao, Y.; Wang, Z.; Li, Z.; Tang, Z. An assessment of urban park access in Shanghai-Implications for the social equity in urban China. Landsc. Urban Plan. 2017, 157, 383-393. [CrossRef]

20. Wei, F. Greener urbanization? Changing accessibility to parks in China. Landsc. Urban Plan. 2017, 157, 542-552. [CrossRef]

21. Wüstemann, H.; Kalisch, D.; Kolbe, J. Access to urban green space and environmental inequalities in Germany. Landsc. Urban Plan. 2017, 164, 124-131. [CrossRef]

22. Gallego, F.J. A population density grid of the European Union. Popul. Environ. 2010, 31, 460-473. [CrossRef]

23. Flatø, H. Socioeconomic status, air pollution and desire for local environmental protection in China: Insights from national survey data. J. Environ. Plan. Manag. 2019, 63, 1-18. [CrossRef]

24. National Bureau of Statistics, China. Available online: http://www.stats.gov.cn/tjsj/ndsj/ (accessed on 23 October 2020).

25. Deng, X.Z.; Huang, J.K.; Rozelle, S.; Uchida, E. Economic Growth and the Expansion of Urban Land in China. Urban Stud. 2010, 47, 813-843. [CrossRef]

26. Xiao, J.; Shen, Y.; Ge, J.; Tateishi, R.; Tang, C.; Liang, Y.; Huang, Z. Evaluating urban expansion and land use change in Shijiazhuang, China, by using GIS and remote sensing. Landsc. Urban Plan. 2006, 75, 69-80. [CrossRef] 
27. Gu, X.; Tao, S.; Dai, B. Spatial accessibility of country parks in Shanghai, China. Urban For. Urban Green. 2017, 27, 373-382. [CrossRef]

28. Bureau of Statistics, Nanjing, China. Available online: http://tjj.nanjing.gov.cn/bmfw/njtjnj/ (accessed on 23 October 2020).

29. Diniz-Filho, J.A.F.; Bini, L.M.; Hawkins, B.A. Spatial Autocorrelation and Red Herrings in Geographical Ecology. Glob. Ecol. Biogeogr. 2003, 12, 53-64. [CrossRef]

30. Gu, X.; Li, Q.; Chand, S. Factors influencing residents' access to and use of country parks in Shanghai, China. Cities 2020, 97, 102501. [CrossRef]

31. Jin, C. Study on Pedestrian Corssing Characteristics. Ph.D. Thesis, Jilin University, Jilin, China, 2007.

32. Yu, S.; Zhu, X.; He, Q. An Assessment of Urban Park Access Using House-Level Data in Urban China: Through the Lens of Social Equity. Int. J. Environ. Res. Public Health 2020, 17, 2349. [CrossRef]

33. Sutton, P.; Roberts, D.; Elvidge, C.; Baugh, K. Census from Heaven: An estimate of the global human population using night-time satellite imagery. Int. J. Remote Sens. 2001, 22, 3061-3076. [CrossRef]

34. Kraus, S.P.; Senger, L.W.; Ryerson, J.M. Estimating population from photographically determined residential land use types. Remote Sens. Environ. 1974, 3, 35-42. [CrossRef]

35. Bai, Z.; Wang, J.; Fei, Y. Research progress in spatialization of population data. Prog. Geogr. 2010, 32, 1692-1702. (In Chinese)

36. Han, D.; Yang, X.; Cai, H.; Xu, X.; Qiao, Z.; Cheng, C.; Dong, N.; Huang, D.; Liu, A. Modelling spatial distribution of fine-scale populations based on residential properties. Int. J. Remote Sens. 2019, 40, 5287-5300. [CrossRef]

37. Dong, N.; Yang, X.; Cai, H. A method for demographic data spatialization based on residential space attributes. Prog. Geogr. 2016, 35, 1317-1328. (In Chinese)

38. Mears, M.; Brindley, P. Measuring Urban Greenspace Distribution Equity: The Importance of Appropriate Methodological Approaches. ISPRS Int. Geo-Inf. 2019, 8, 286. [CrossRef]

39. Logan, T.M.; Williams, T.G.; Nisbet, A.J.; Liberman, K.D.; Zuo, C.T.; Guikema, S.D. Evaluating urban accessibility: Leveraging open-source data and analytics to overcome existing limitations. Env. Plan. B-Urban Anal. CIty Sci. 2017, 46, 897-913. [CrossRef]

40. Jin, X.; Long, Y.; Sun, W.; Lu, Y.; Yang, X.; Tang, J. Evaluating cities' vitality and identifying ghost cities in China with emerging geographical data. Cities 2017, 63, 98-109. [CrossRef]

41. Chen, S.; Sleipness, O.; Xu, Y.; Park, K.; Christensen, K. A systematic review of alternative protocols for evaluating non-spatial dimensions of urban parks. Urban For. Urban Green. 2020, 53, 126718. [CrossRef]

Publisher's Note: MDPI stays neutral with regard to jurisdictional claims in published maps and institutional affiliations.

(C) 2020 by the authors. Licensee MDPI, Basel, Switzerland. This article is an open access article distributed under the terms and conditions of the Creative Commons Attribution (CC BY) license (http://creativecommons.org/licenses/by/4.0/). 